ARTICLE

\title{
Ion-specific ice recrystallization provides a facile approach for the fabrication of porous materials
}

Shuwang Wu ${ }^{1,2, \star}$, Chongqin Zhu $u^{3,4, \star}$, Zhiyuan $\mathrm{He}^{1,2}$, Han Xue ${ }^{1,2}$, Qingrui Fan ${ }^{1,2}$, Yanlin Song ${ }^{1,2}$, Joseph S. Francisco ${ }^{3}$, Xiao Cheng Zeng ${ }^{3,4} \&$ Jianjun Wang ${ }^{1,2}$

Ice recrystallization is of great importance to both fundamental research and practical applications, however understanding and controlling ice recrystallization processes remains challenging. Here, we report the discovery of an ion-specific effect on ice recrystallization. By simply changing the initial type and concentration of ions in an aqueous solution, the size of ice grains after recrystallization can be tuned from $27.4 \pm 4.1$ to $277.5 \pm 30.9 \mu \mathrm{m}$. Molecular dynamics simulations show that the ability of the ion to be incorporated into the ice phase plays a key role in the ultimate size of the ice grains after recrystallization. Moreover, by using recrystallized ice crystals as templates, 2D and 3D porous networks with tuneable pore sizes could be prepared from various materials, for example, $\mathrm{NaBr}$, collagen, quantum dots, silver and polystyrene colloids. These porous materials are suitable for a wide range of applications, for example, in organic electronics, catalysis and bioengineering.

\footnotetext{
${ }^{1}$ Key Laboratory of Green Printing, Institute of Chemistry, Chinese Academy of Sciences, Beijing 100190, China. ${ }^{2}$ School of Chemistry and Chemical Engineering, University of Chinese Academy of Sciences, Beijing 100049, China. ${ }^{3}$ Department of Chemistry, University of Nebraska-Lincoln, Lincoln, Nebraska 68588, USA. ${ }^{4}$ Beijing Advanced Innovation Center for Soft Matter Science and Engineering, Beijing University of Chemical Technology, Beijing 100029, China. * These authors contributed equally to this work. Correspondence and requests for materials should be addressed to X.C.Z. (email: xzeng1@unl.edu) or to J.W. (email: wangj220@iccas.ac.cn).
} 
ce recrystallization is a ubiquitous phenomenon in nature ${ }^{1-4}$, with consequences for our daily lives, including the survival of living organisms ${ }^{5-9}$ in subzero environments, food storage ${ }^{10}$, glacial flow in cold climates (such as Antarctica and Greenland $)^{11}$, sea current changes ${ }^{12}$ and decreases in ozone concentration $^{13}$ in the stratosphere. Ice recrystallization occurs mainly through the process of Ostwald ripening ${ }^{14}$. In this process, large ice crystals grow at the expense of small ones, which results in an increase in the mean crystal size and a decrease in the total number of crystals. Impurities are often included during ice recrystallization $^{15-17}$. For example, it has been suggested that recrystallization of sea ice led to the formation of prebiotic materials, which may have important implications for the emergence of life ${ }^{18}$. Therefore, studying the effects of impurities on ice recrystallization is highly desirable ${ }^{19,20}$, particularly ion-specific effects on ice recrystallization. For example, does the ability of ice crystals to incorporate ions vary for different types of ions? Can ions significantly influence the size of ice grains after recrystallization?

Ion specificity, also known as the Hofmeister effect, was first discovered by Franz Hofmeister in 1888 (ref. 21). This effect refers to the intriguing phenomenon wherein different types of ions can have profoundly different effects on the stability of proteins. Subsequently, additional evidence for ion-specific effects on other physico-chemical properties and processes have been revealed, such as effects on surface tension, protein folding, protein crystallization, enzymatic activity and colloidal assembly ${ }^{22-27}$. Most recently, an ion-specific effect on heterogeneous ice nucleation has been reported ${ }^{28}$. However, to our knowledge, the effect of ion specificity on ice recrystallization has not been studied.

Herein, we report both experimental and theoretical evidence of ion specificity in regulating ice recrystallization. We find that the size of ice grains after recrystallization can be regulated by more than one order of magnitude by simply changing the type or concentration of ions in the aqueous solution at the initial stage. This phenomenon can be understood on the molecular level through molecular dynamics (MD) simulations. Specifically, our simulation demonstrates that the ability of ice crystals to incorporate ions and the stability of the liquid layer between crystal domains both exhibit an ion-specific effect. More remarkably, we show that ion-specific recrystallized ice crystals can be exploited as a template-based approach for the facile fabrication of various $2 \mathrm{D}$ and $3 \mathrm{D}$ porous materials, and the pore size can be controlled simply by regulating the ice grain size via changes in the type and concentration of ions. As an alternative to conventional ice templates created via a directional ice growth process, this method provides a different approach to fabricating porous materials ${ }^{29-33}$.

\section{Results}

Effect of ions on ice recrystallization. We quantitatively evaluated the ability of various ions to regulate ice recrystallization with the 'splat-cooling' assay ${ }^{34}$ (Supplementary Fig. 1). Briefly, aqueous solutions of different ions were rapidly frozen (at quenching temperatures ranging from -30 to $-90^{\circ} \mathrm{C}$ ) on a flat solid substrate to form polycrystalline ice crystals, and then the ice crystals were annealed at a higher temperature (for example, $-6{ }^{\circ} \mathrm{C}$ ). During the annealing process, the mean size of the ice grains increases while the total number of ice grains decreases (Supplementary Fig. 2). Figure 1 shows typical annealed ice grains obtained from pure water and three types of salt solutions $(0.01 \mathrm{M} \mathrm{NaF}, \mathrm{NaBr}$ and $\mathrm{NaI})$. The mean grain size of the ice crystals obtained from pure water is $158.3 \pm 11.2 \mu \mathrm{m}$ (Fig. 1a) and is much larger than that obtained from the $\mathrm{NaF}$ solution $(34.2 \pm 4.7 \mu \mathrm{m}$; Fig. 1b). In stark contrast, the mean grain size of ice crystals obtained from the $\mathrm{NaI}$ solution is $228.7 \pm 20.1 \mu \mathrm{m}$ and
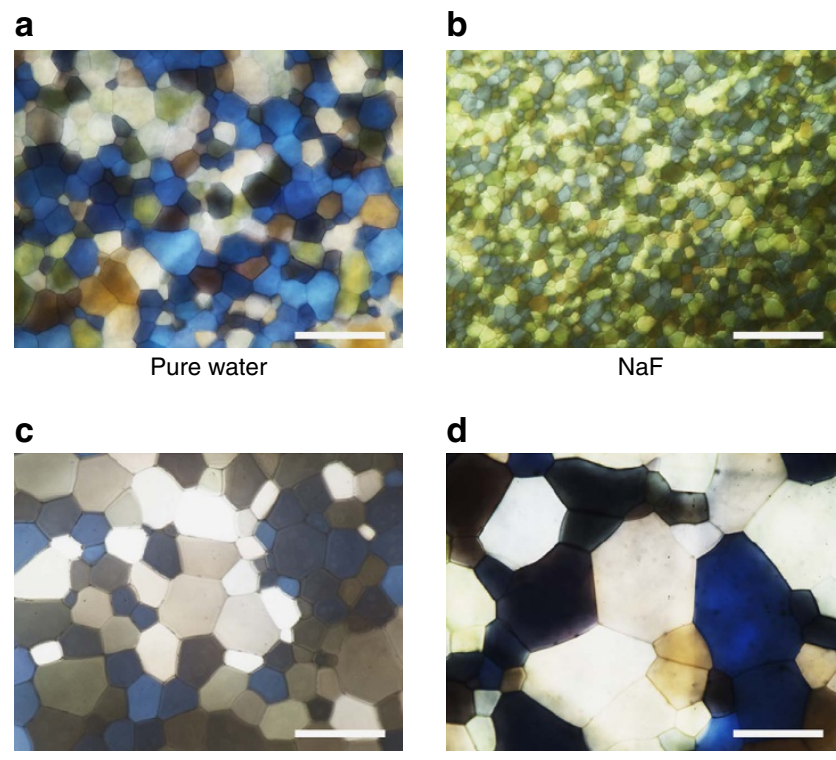

$\mathrm{NaBr}$

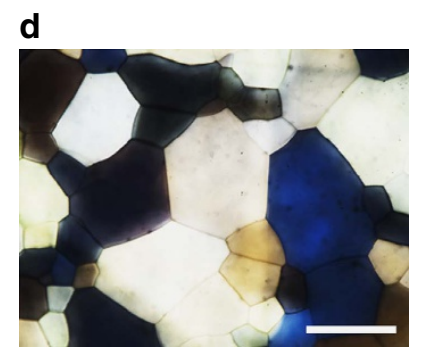

$\mathrm{Nal}$

Figure 1 | Polarized optical microscopy images of polycrystalline ice

crystals. (a-d) show the typical grain size of ice crystals after rapid freezing and annealing at a higher temperature of pure water, $\mathrm{NaF}, \mathrm{NaBr}$ and $\mathrm{Nal}$ aqueous solutions, respectively. Clearly, anions have a distinct effect on ice recrystallization. Aqueous solution droplets $(20 \mu \mathrm{l})$ were dropped onto a silicon wafer substrate from a height of $1.5 \mathrm{~m}$. The wafer surface temperature was $-60^{\circ} \mathrm{C}$, and the substrate was placed in a $\mathrm{N}_{2}$ environment to prevent water condensation and ice formation. Then, the ice crystals were annealed at $-6^{\circ} \mathrm{C}$ for $45 \mathrm{~min}$. The concentration of the salt solution was $0.01 \mathrm{M}$. The scale bar is $200 \mu \mathrm{m}$.

is much larger than that obtained from pure water. Interestingly, the mean grain size of ice crystals obtained from the $\mathrm{NaBr}$ solution $(165.8 \pm 12.5 \mu \mathrm{m})$ is comparable to that obtained from pure water. Clearly, the mean size of ice crystals can be regulated to be either much smaller than, comparable to or much larger than that obtained from pure water, simply by changing the anions in the initial solution.

To confirm the ion-specific effect on ice recrystallization, several more ions were studied (Fig. 2). The mean grain size of ice crystals obtained from salt solutions with various anions but the same $\mathrm{Na}^{+}$cation follows the sequence: $\mathrm{HPO}_{4}^{2-}<\mathrm{SO}_{4}^{2-}$ $<\mathrm{F}^{-}<\mathrm{AC}^{-}<\mathrm{SCN}^{-}<\mathrm{ClO}_{4}^{-}<\mathrm{Br}^{-}<\mathrm{Cl}^{-}<\mathrm{NO}_{3}^{-}<\mathrm{I}^{-}$. Note that the ice grains produced from the $\mathrm{HPO}_{4}^{2-}, \mathrm{SO}_{4}^{2-}$, $\mathrm{F}^{-}$and $\mathrm{AC}^{-}$salt solutions are much smaller than those obtained from pure water, whereas the ice grains produced from $\mathrm{Cl}^{-}, \mathrm{NO}_{3}^{-}$and $\mathrm{I}^{-}$are much larger than those obtained from pure water. The ice crystal grain size from salt solutions of different cations but with the same $\mathrm{Cl}^{-}$anion follows the sequence $\mathrm{NH}_{4}^{+}<\mathrm{Mg}^{2+}<\mathrm{Ca}^{+}<\mathrm{Li}^{+}<\mathrm{TMA}^{+}<\mathrm{Na}^{+}<\mathrm{Gua}^{+}$ $<\mathrm{K}^{+}<\mathrm{Cs}^{+}$(Fig. 2b). As shown in Fig. 2b, the ice crystal grains obtained from $\mathrm{NH}_{4}^{+}, \mathrm{Mg}^{2+}, \mathrm{Ca}^{+}, \mathrm{Li}^{+}$and $\mathrm{TMA}^{+}$ solutions are smaller than those obtained from pure water, and the ice crystal grains obtained from $\mathrm{Na}^{+}, \mathrm{Gua}^{+}, \mathrm{K}^{+}$and $\mathrm{Cs}+$ solutions are larger than those obtained from pure water. Note that the ability of anions to modify ice recrystallization is greater than that of cations, which is consistent with other ion specificities $^{35}$. Therefore, our work demonstrates evidence of the Hofmeister effect on ice recrystallization.

Various factors that can affect ice recrystallization. To gain insight into the ice recrystallization process, the size evolution of the ice crystals as a function of the annealing time was analysed 
a

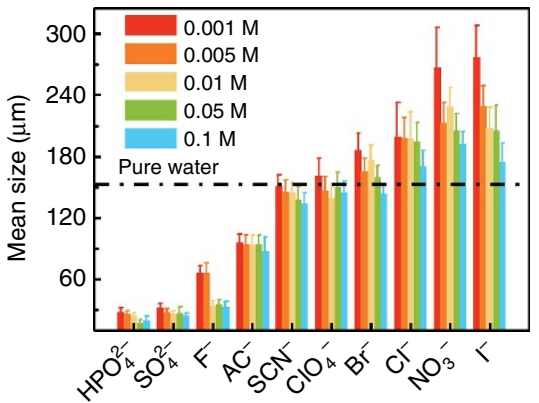

b

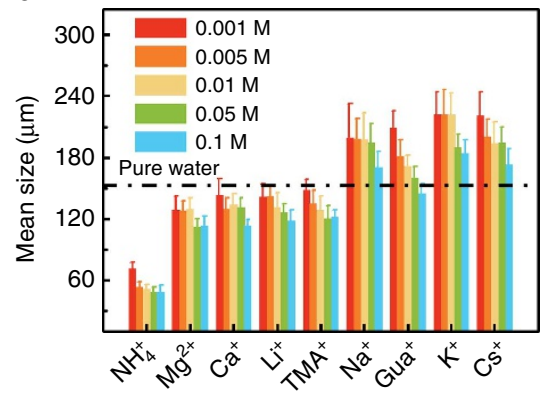

Figure 2 | Effect of ions on tuning ice recrystallization. (a) The effect of anions in tuning the ice crystal size. $\mathrm{Na}^{+}$was used as the common counter-ion. (b) The effect of cations in tuning the ice crystal size. $\mathrm{Cl}^{-}$was used as the common counter ion. Five concentrations were tested for each ion. The mean grain sizes obtained from aqueous solutions of different ions were measured after the polycrystalline ice was annealed at $-6^{\circ} \mathrm{C}$ for 45 min, while the initial quench temperature was $-60^{\circ} \mathrm{C}$. Error bars represent the s.d. of the size of thirty ice crystals. The dash-dot line is the mean grain size from pure water as a reference.

(Supplementary Figs 3 and 4), as shown in Fig. 3a. For the ice crystals obtained from three aqueous solutions and from pure water, all the ice grains experience an initial growth at the expense of small ice crystals and then level off after $\sim 45 \mathrm{~min}$. Note that both the initial growth rate and the mean grain size after $45 \mathrm{~min}$ increase in the sequence of $\mathrm{NaF}<$ pure water $<\mathrm{NaBr}<\mathrm{NaI}$ (Fig. 3a).

There are two ways to influence the ice recrystallization process with ions: through nucleation and through ice growth ${ }^{34,36}$. To determine which process is more important, the effects of the quench and annealing temperatures on the mean size of the ice grains from different salt solutions $(0.01 \mathrm{M})$ and pure water were investigated, as shown in Fig. 3b,c. Our experiments show that the quenching temperature only slightly affects the mean grain size, which implies that the nucleation process plays a small role in the mean grain size at this ion concentration, and the nucleation process is mainly dictated by the quenching temperature. By contrast, the annealing temperature plays a key role in dictating the mean size at this ion concentration, which indicates a pronounced effect of the crystal growth process in ice recrystallization (Supplementary Tables 1-5).

We further studied the effect of the salt concentration on the ion specificity in regulating ice recrystallization (Fig. 3d; Supplementary Fig. 5). When the salt concentration increases stepwise from $10^{-6}$ to $10^{-1} \mathrm{M}$, the mean grain size of recrystallized ice crystals follows the sequence of $\mathrm{F}^{-}<\mathrm{Br}^{-}<\mathrm{I}^{-}$. Moreover, the grain size first increases and then decreases for all ice crystals obtained from NaF, $\mathrm{NaBr}$ and $\mathrm{NaI}$ solutions. The mean grain size of ice crystals from $\mathrm{NaF}, \mathrm{NaBr}$ and $\mathrm{NaI}$ solutions peaks at salt concentrations of $10^{-5} \mathrm{M}, 10^{-4} \mathrm{M}$ and $10^{-3} \mathrm{M}$, respectively, and the corresponding values of the grain size are $138.9 \pm 18.2 \mu \mathrm{m}, 238.2 \pm 22.6 \mu \mathrm{m}$ and $277.5 \pm 30.9 \mu \mathrm{m}$. The same sequence is observed in the effects of the quench temperature and the annealing time and temperature (Supplementary Fig. $3 \mathrm{a}-\mathrm{c}$, respectively). Note that previous studies of the evolution of the freezing potential ${ }^{37,38}$ as ice crystals grow in aqueous salt solutions have revealed the same trend as that of the effect of the salt concentration on ice recrystallization. Namely, both exhibit a trend wherein the effect is to first increase and then decrease, which suggests that the regulation of ice recrystallization by ions in our experiments may be due to different amounts of ions in the ice crystals.

Mechanistic investigation of ice recrystallization. Questions arise as to (1) why all the ions lead to this generic trend, namely, a maximum in the mean size versus ion concentration curve (Fig. 3d) and (2) why the critical ionic concentration (corresponding to the maximum in Fig. 3d) follows the sequence of $\mathrm{F}^{-}<\mathrm{Br}^{-}<\mathrm{I}^{-}$? Previous studies have indicated that the ions generally suppress ice nucleation ${ }^{39}$. In other words, due to the added ions, the likelihood of nucleus formation in aqueous solutions tends to decrease in comparison to that in pure water. Moreover, at extremely low-salt concentrations, the ions affect ice nucleation more strongly than ice growth. As a result, the mean grain size of ice crystals should increase if ice formation occurs at very low-salt concentrations, regardless of the type of ions. Note that this conclusion is consistent with a previous study of the ion-specific effect on heterogeneous ice nucleation ${ }^{28}$. In that study, the experiments showed that the ion-specific effect on ice nucleation followed the sequence $\mathrm{F}^{-}>\mathrm{Br}^{-}>\mathrm{I}^{-}$. In other words, among the three anions, $\mathrm{F}^{-}$leads to the largest decrease in the incipient temperature of ice formation. As a result, the critical ionic concentration is expected to follow the sequence $\mathrm{F}^{-}<\mathrm{Br}^{-}<\mathrm{I}^{-}$, because the lowest concentration of $\mathrm{F}^{-}$is required to suppress ice nucleation. By contrast, at a relatively high-salt concentration, ice growth is expected to be seriously affected regardless of the type of ion. Therefore, an increase in the ion concentration should lead to a decrease in the grain size.

To gain more insight into the mechanism underlying the ion-specific effect on ice recrystallization, classical MD simulations were performed (see Methods section for details). Snapshots of the systems with $\mathrm{F}^{-}$(Supplementary Fig. 6), $\mathrm{Br}^{-}$and $\mathrm{I}^{-}$anions at different simulation times are shown in Fig. $4 \mathrm{a}-\mathrm{c}$, respectively. The results clearly indicate that $\mathrm{F}^{-}, \mathrm{Br}^{-}$ and $\mathrm{I}^{-}$anions can be incorporated into the ice crystal. As shown in Fig. 4a and Supplementary Movie 1, the addition of ions induced vicinal ice melting at an early stage ( $1.2 \mathrm{~ns})$, whereas at a later equilibrium stage ( $100 \mathrm{~ns}$ ), all $\mathrm{F}^{-}$ions remain in the liquid water phase (with $154 \pm 21$ water molecules). This result is in stark contrast to the situation for $\mathrm{Br}^{-}$and $\mathrm{I}^{-}$ions, as shown in Fig. 4b,c and Supplementary Movies 2 and 3. Only one ion was left in the liquid water phase (with $114 \pm 12$ water molecules for $\mathrm{Br}^{-}$and $87 \pm 19$ water molecules for $\mathrm{I}^{-}$in liquid phase, respectively) and the other two ions were dissolved in the ice phase at the later equilibrium stage $(100 \mathrm{~ns})$. Similar phenomena are also observed at the lower temperature (Supplementary Fig. 7). All these results indicate that (1) $\mathrm{F}^{-}$is the least likely to be incorporated into the ice phase; and (2) the thickness of the remaining vicinal liquid water layer follows the trend $\mathrm{F}^{-}>\mathrm{Br}^{-}>\mathrm{I}^{-}$. Both conclusions provide an explanation as to why the mean grain size after equilibration follows the sequence $\mathrm{F}^{-}<\mathrm{Br}^{-}<\mathrm{I}^{-}$. Because the $\mathrm{F}^{-}$ions tend to remain in the 
a
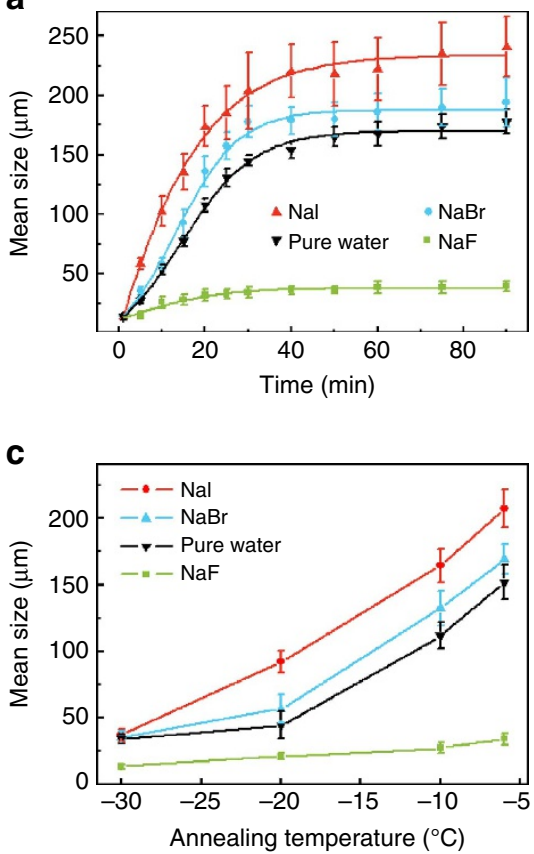

b

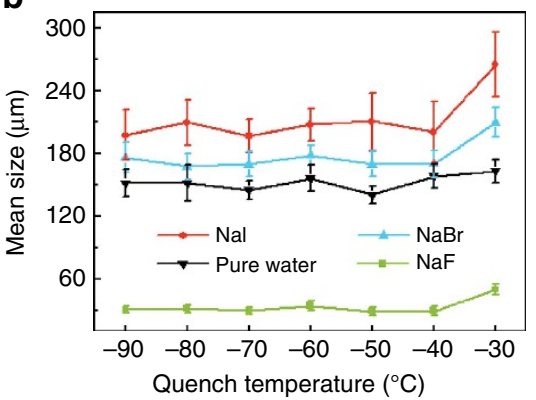

d

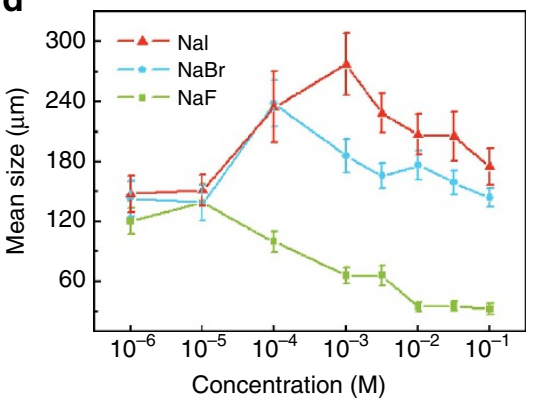

Figure 3 | Grain size variation. The mean grain size of the ice crystals recrystallized from pure water and $\mathrm{NaF}, \mathrm{NaBr}$ and $\mathrm{Nal}$ aqueous solutions at: (a) Different annealing times with the quench temperature of $-60^{\circ} \mathrm{C}$ and annealing temperature of $-6{ }^{\circ} \mathrm{C}$; (b) Various quench temperatures with an annealing temperature of $-6^{\circ} \mathrm{C}$ and annealing time of $45 \mathrm{~min}$; (c) Different annealing temperatures with a quench temperature of $-60^{\circ} \mathrm{C}$ and an annealing time of $45 \mathrm{~min}$; (d) Various concentrations of salts with quench and annealing temperatures of $-60^{\circ} \mathrm{C}$ and $-6^{\circ} \mathrm{C}$, respectively, and an annealing time of $45 \mathrm{~min}$. Note that the mean size of ice crystals obtained in $\mathrm{NaF}, \mathrm{NaBr}$ and Nal peaked at concentrations of $10^{-5} \mathrm{M}, 10^{-4} \mathrm{M}$ and $10^{-3} \mathrm{M}$, respectively. For the experiments shown in (a-c) the concentration of salts was $0.01 \mathrm{M}$. The error bars represent the s.d.

vicinal liquid water layer during ice growth, further ice crystal growth is blocked, which yields smaller ice grains than grains obtained with $\mathrm{Br}^{-}$or $\mathrm{I}^{-}$ions. Note that the same qualitative conclusions can be drawn from independent test simulations with the conventional Nosé-Hoover thermostat (Supplementary Fig. 8).

To quantitatively evaluate the tendency of halide ions to be incorporated into an ice crystal, we performed another series of test MD simulations to compute the average interaction energy of an ion with the surrounding water molecules in the bulk ice $\left(E_{\mathrm{X} \text {-ice }}\right)$ (calculation values are marked by the height of red bars in Fig. 4d). For comparison, the interaction energy of a water molecule in bulk ice is also computed. Our simulation shows that this energy is $\sim 1.69 \pm 0.10 \mathrm{eV}$, which is approximately four times that of the typical hydrogen-bonding energy in bulk ice. However, the interaction energy of an ion with the surrounding water molecules in the bulk ice is much greater, and their magnitudes follow the sequence $\mathrm{F}^{-}>\mathrm{Br}^{-}>\mathrm{I}^{-}$. The largest difference in the required energy between $\mathrm{F}^{-}$and a water molecule in the bulk ice indicates the highest degrees of disruption to the local ice structure near the $\mathrm{F}^{-}$ions, or the lowest tendency of $\mathrm{F}^{-}$to be incorporated into the ice crystal. We further quantified the degrees of disruption to the local ice structure due to the ions by computing the radial distribution functions (RDF) of $\mathrm{O}$ atoms in pure bulk ice and the $\mathrm{O}$ atoms surrounding the halide ions (Fig. 4e). The first peak appears at a distance of $2.78 \AA$, regardless of the presence or absence of ions. The second peak at a distance of $\sim 3.46 \AA$, however, is entirely due to the presence of $\mathrm{F}^{-}$, whereas the second peak at a distance of $\sim 4.51 \AA$ is observed for the pure ice or in the presence of $\mathrm{Br}^{-}$and $\mathrm{I}^{-}$. These results offer a molecular-level explanation for why $\mathrm{F}^{-}$is the least likely ion to be incorporated into the ice crystals. This conclusion can be further supported by the potential energy increase in the pure ice crystal due to the presence of the embedded ions (the values of energy increase are marked by the height of cyan bars in Fig. 4d). With the addition of ions, the net potential energy of the bulk ice (excluding the central water molecule or the ion) is increased, and this energy increase follows the sequence $\mathrm{F}^{-}>\mathrm{Br}^{-}>\mathrm{I}^{-}$, which indicates that the tendency of the halide ions to be incorporated into the ice slab follows the sequence $\mathrm{F}^{-}<\mathrm{Br}^{-}<\mathrm{I}^{-}$. Therefore, a molecular-level mechanism of ion-specificity in ice recrystallization is provided.

Facile synthesis of $2 \mathrm{D}$ and $3 \mathrm{D}$ porous materials. As shown above, the size of recrystallized ice grains can be easily regulated by changing the ions or ion concentration in the initial aqueous solution, and the variation in the size of the ice grains can be more than one order of magnitude. Another important feature of recrystallized ice crystals is that most of the impurities are excluded from the ice grain and left at the grain boundaries after recrystallization ${ }^{40,41}$. Therefore, we can take advantage of these features and utilize the recrystallized ice grains as templates to fabricate various $2 \mathrm{D}$ and $3 \mathrm{D}$ porous materials with different pore sizes. Figure $5 \mathrm{a}$ shows a series of $2 \mathrm{D}$ collagen meshes with variable pore sizes, which demonstrates that the pore size can be tuned by either changing the type or concentration of ions, whereas Fig. 5b displays that $2 \mathrm{D}$ and $3 \mathrm{D}$ porous materials can be fabricated (Fig. 5b) in view of their potential applications ${ }^{42,43}$. The porous materials ${ }^{44-46}$ can be fabricated by first recrystallizing aqueous salt solutions with various materials, such as inorganic materials, biopolymers, quantum dots, metallic particles and polymer colloids (Supplementary Figs 9-14), and then dried under vacuum. As exhibited in Fig. 5c, the same general method can be used to prepare porous materials from a wide range of constituents and for various applications. For example, pore size 
a

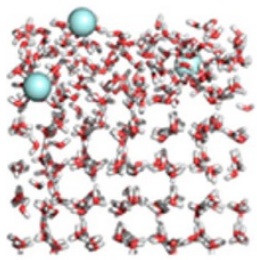

$0.0 \mathrm{~ns}$

b

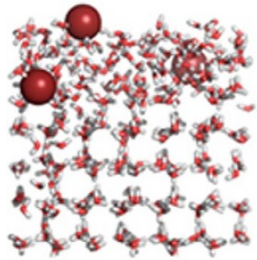

$0.0 \mathrm{~ns}$

C

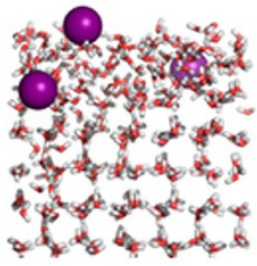

0.0 ns

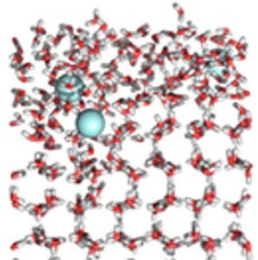

$1.2 \mathrm{~ns}$

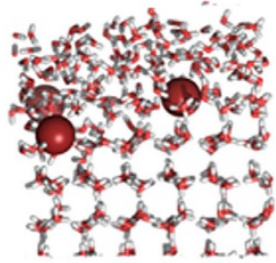

$4.0 \mathrm{~ns}$

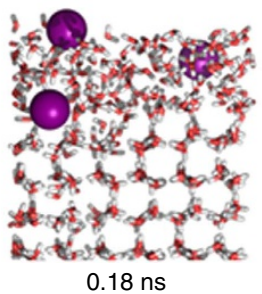

$0.18 \mathrm{~ns}$

d

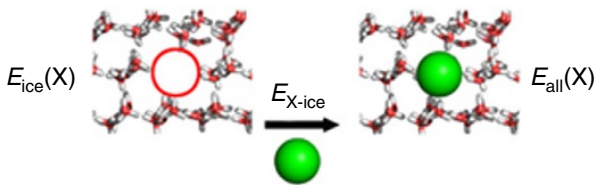

Water $/ \mathrm{F}^{-} / \mathrm{Br}^{-} / \mathrm{I}^{-}$

$E_{\mathrm{X} \text {-ice }}=E_{\text {ice }}(\mathrm{X})-E_{\mathrm{all}}(\mathrm{X})$

$\Delta E_{\mathrm{X}}=E_{\text {ice }}(\mathrm{X})-E_{\text {ice }}$ (water)

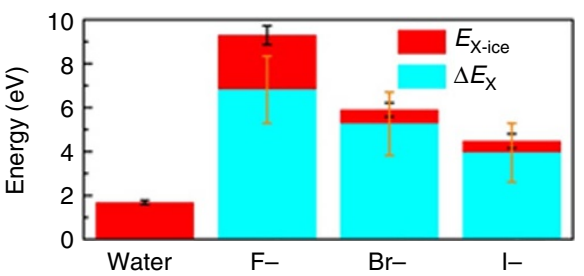

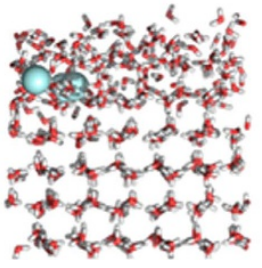

$80.0 \mathrm{~ns}$

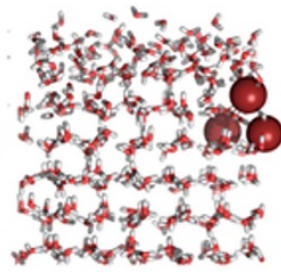

$60.0 \mathrm{~ns}$

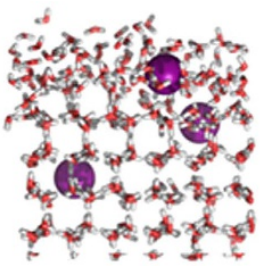

90.0 ns

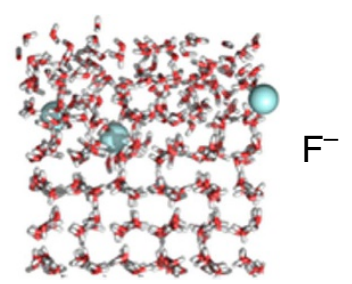

100.0 ns

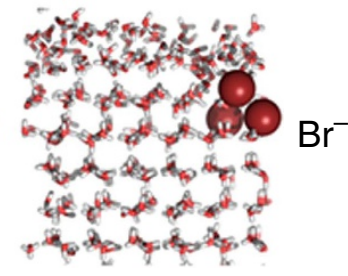

$100.0 \mathrm{~ns}$

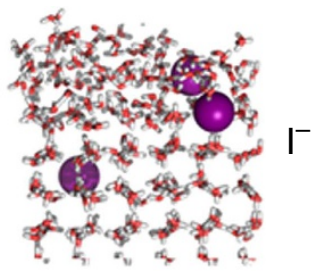

100.0 ns

e

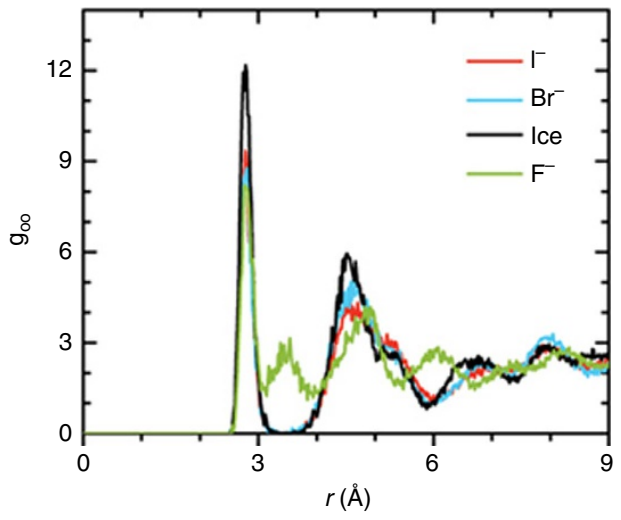

Figure 4 | Molecular dynamics simulations. Snapshots of the MD simulations for illustrating the effect of (a) $\mathrm{F}^{-}$, (b) $\mathrm{Br}^{-}$or (c) I ${ }^{-}$ions on ice formation at $-13^{\circ} \mathrm{C}$. (d) Results of test MD simulation (see Methods) for computing average interaction energy ( $E_{X \text {-ice }}$ ) of a water molecule or an ion with the surrounding water molecules in the bulk ice are depicted by the height of red bars (results being averaged over 50 configurations in the last 100 ps of the 1 ns test $M D$ simulations). Here, $E_{\text {all }}(X)$ denotes the total potential energy of the system after the replacement of two tagged water molecules with $X$ $\left(\mathrm{X}=\right.$ water, $\mathrm{F}^{-}, \mathrm{Br}^{-}$or $\left.\mathrm{I}^{-}\right)$and $\mathrm{Na}^{+}$. The potential energy increase $\left(\Delta E_{\mathrm{X}}\right)$ for the pure ice crystal due to the presence of the embedded ions is marked by the height of cyan bars. The root-mean-square error bars (black and yellow) are calculated based on the data of 50 configures in the last 100 ps.

(e) Computed radial distribution functions of $\mathrm{O}$ atoms in pure ice and $\mathrm{O}$ atoms surrounding the halide ions.

plays a key role in bioengineering applications, such as cell attachment $^{47}$, cell culturing ${ }^{4,49}$ and cell separation.

\section{Discussion}

In summary, we have shown clear evidence that ions can significantly affect ice recrystallization, but the degree of influence differs dramatically, depending on the type of ion. Remarkably, we find that these ions could be ranked as a Hofmeister series based on their ability to tune the ice recrystallization. MD simulation results indicate that, during the ice recrystallization, relatively high charge density ions such as $\mathrm{F}^{-}$prefer to stay at the ice-water interface and thus inhibit ice growth. By contrast, ions of relatively low charge density, such as $\mathrm{I}^{-}$, are more likely to be incorporated into ice crystals and thus inhibit ice growth to a lesser extent. Most importantly, we found that when the ice crystals were used as templates for fabricating $2 \mathrm{D}$ and $3 \mathrm{D}$ porous materials, the pore size can be easily tuned by regulating the mean grain size with different ions or ion concentrations. The generic approach of using recrystallization to regulate ice templates 
a
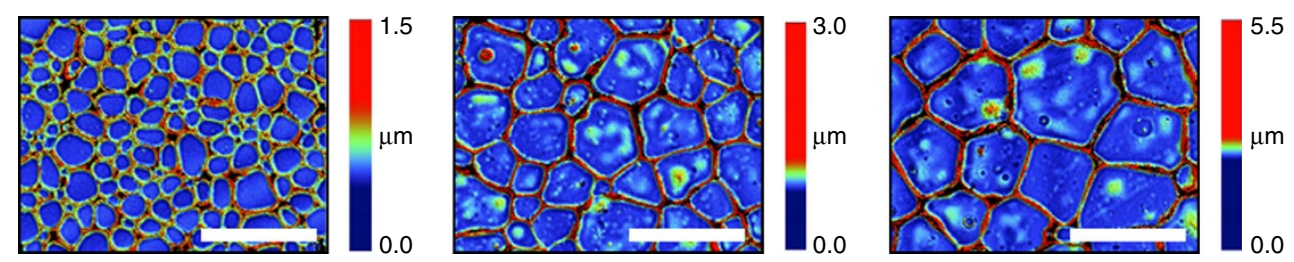

b
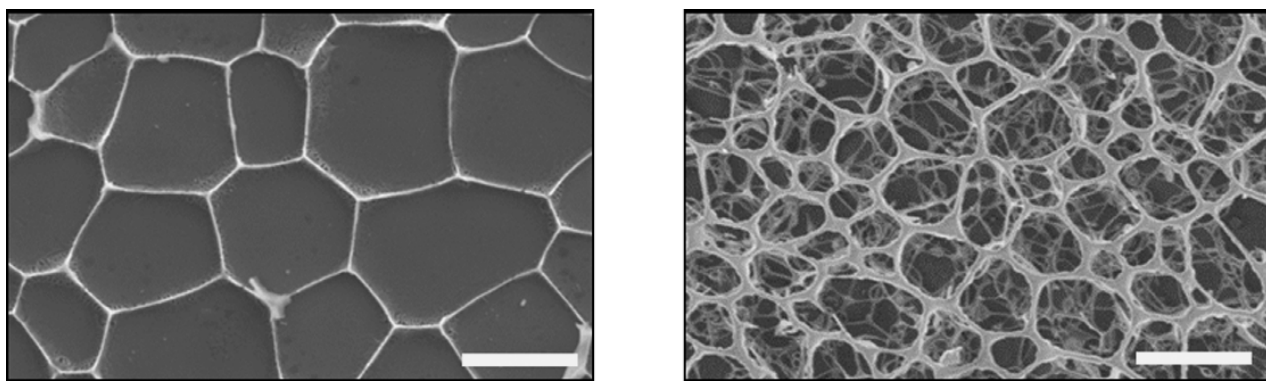

C

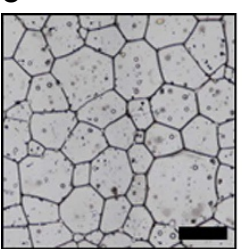

$\mathrm{NaBr}$

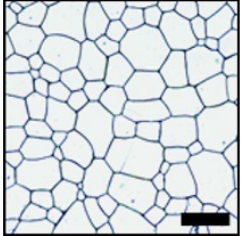

Collagen

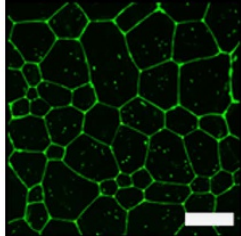

Quantum dots

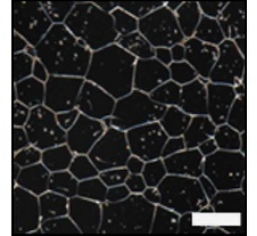

$\mathrm{Ag}$

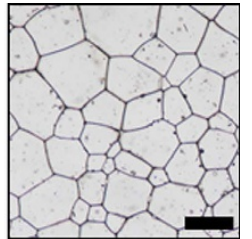

PS colloid

Figure 5 | Porous materials prepared using recrystallized ice crystals as template. The images in (a) show that the size of the 2D meshes can be easily regulated by changing the ions or the ion concentration in the initial aqueous solution. (b) The 2D and 3D porous materials can be prepared with recrystallized ice crystals as the template. (c) Various materials such inorganic salts, collagen, quantum dots, metallic nanoparticles and polystyrene colloids can be used to prepare porous materials. All the scale bars are $200 \mu \mathrm{m}$.

provides a way to fabricate $2 \mathrm{D}$ and $3 \mathrm{D}$ structures based on a wide variety of materials, from small molecules to nanoparticles.

\section{Methods \\ Ice recrystallization assay. All salts were purchased from Sigma-Aldrich. And the water used for preparing the electrolytes solutions was Milli-Q (18.2 M 2 ) water Ice recrystallization was performed via the splat-cooling method as described previously ${ }^{34,50}$ (also see Supplementary Methods). The experimental apparatus was composed of a Nikon polarized optical microscope (LV100ND, Japan) equipped with a digital camera (Nikon Y-TV55, Japan) and a Linkman (C194) cooling stage shown in Supplementary Fig. 1. The experimental procedure is described as follows: a $20 \mu \mathrm{l}$ droplet of electrolyte solution was dropped onto the cover glass precooled to $-60^{\circ} \mathrm{C}$ from a height of $1.5 \mathrm{~m}$ forming a piece of polycrystalline ice. The temperature was increased to $-6^{\circ} \mathrm{C}$ at a rate of $25^{\circ} \mathrm{C} \mathrm{min}-1$, and then the samples were annealed at this temperature for $45 \mathrm{~min}$. Thereafter, the ice was imaged randomly. For every sample, five experimental runs were performed. To plot each figure, the size of the largest 10 grains was measured using Nano-Measure 1.2. Among these 50 data, 30 corresponding to the largest grains were chosen to calculate the mean size. One way ANOVA and $2^{2}$ factorial design was used to analyse the mean size results (Supplementary Tables 1-6).}

Synthesis of 2D and 3D porous materials. Collagen (from bovine Achilles tendon, hydrolysis product, 1000 Dalton) was purchased from J\&K Chemicals. Aqueous salt solutions of various materials $(0.01 \mathrm{M} \mathrm{NaF}, \mathrm{NaBr}$ and $\mathrm{NaI})$ were splat-frozen and annealed at $-6{ }^{\circ} \mathrm{C}$ for $45 \mathrm{~min}$. Then, the samples were freeze-dried using a freeze dryer (FD-1A-50) to obtain the 2D and 3D materials. To obtain the $2 \mathrm{D}$ porous collagen, the polycrystalline ice needs to be as thin as possible. Hence we set the splat-freezing height at $1.8 \mathrm{~m}$ to form a polycrystalline ice layer $<10 \mu \mathrm{m}$ (ref. 51). After annealing at $-6{ }^{\circ} \mathrm{C}$ for $45 \mathrm{~min}$, only one layer of polycrystalline ice is formed. When preparing $3 \mathrm{D}$ structures, the splat-freezing height was set at $1 \mathrm{~m}$, and after one droplet was splat-frozen, another droplet was splat-frozen on the top of the previous one. The splat-freezing process was repeated many times as needed to form multi-layered polycrystalline ice. Then multi-layered polycrystalline ice was annealed at $-6^{\circ} \mathrm{C}$ for $45 \mathrm{~min}$. After sublimation of ice crystals, the $3 \mathrm{D}$ interconnected network was retained. The $1 \mathrm{wt} \%$ collagen solution was utilized to obtain $2 \mathrm{D}$ one-layer meshes and $5 \mathrm{wt} \%$ collagen solution was used to make 3D interconnected network.

Molecular dynamics simulations. The MD simulation system consisted of 1280 water molecules, $3 \mathrm{Na}^{+}$ions and 3 anions $\left(\mathrm{F}^{-}, \mathrm{Br}^{-}\right.$or $\left.\mathrm{I}^{-}\right)$. The initial configuration was prepared by bringing together an ice slab of 958 water molecules (per supercell) with two separate liquid slabs, each having 164 water molecules (per supercell). All three slabs were separately equilibrated at $-13^{\circ} \mathrm{C}$ for $1 \mathrm{~ns}$. Next, the two liquid slabs were placed in contact with the left and right surfaces of the ice slab (the surface normal is in the $z$-direction) (Supplementary Fig. 6), within a larger simulation box with a length of $10 \mathrm{~nm}$ in the $z$-axis and a lateral area of $2.72 \times 2.35 \mathrm{~nm}^{2}$. The system was then equilibrated for $1 \mathrm{~ns}$. Last, three water molecules in the left liquid water slab were replaced with $\mathrm{Br}^{-}$anions, and three water molecules in the right liquid water slab were replaced with $\mathrm{Na}^{+}$cations. The entire system was then equilibrated for $\sim 1$ ns. Thus, the whole system was effectively a quasi-two-dimensional hybrid slab. Periodic boundary conditions were applied in the $x$ and $y$ directions.

The MD simulations for the two-phase systems illustrated above were carried out using the LAMMPS ${ }^{52}$ software. The TIP4P/ICE water model was adopted. The interaction parameters for ions were taken from the OPLS force field. The LINCS algorithm ${ }^{53}$ was employed to treat the constraints in the model. The van der Waals forces were truncated at $10 \AA$. When the long-range dispersion correction was applied, the relative root-mean-square error in force was found to be $<10^{-4}$. The particle-mesh Ewald method ${ }^{54}$ was used to treat long-range Coulomb interactions. The particle-mesh Ewald parameters were chosen such that the relative error in force was comparable to that of the Lennard-Jones interactions $\left(<5 \times 10^{-4}\right)$. Specifically, the real space cut-off distance was $10 \AA$. The charge grid spacing was $1 \AA$, and the fourth order B-splines were used for interpolation. The leap-frog Verlet integration algorithm with a time step of $1 \mathrm{fs}$ was used for the MD simulation. To rule out the latent-heat-dissipation effects, the hybrid microcanonical-canonical ensemble is employed ${ }^{55}$. As shown in Supplementary Fig. 16, the molecules whose centres of mass lie in a half region of the simulation box $(\mathrm{z}<5 \mathrm{~nm})$, away from the interface, are subjected to $N V T$ dynamics $\left(T=-13^{\circ} \mathrm{C}\right)$, while the molecules lie in the other half region of the simulation box 
( $>5 \mathrm{~nm}$ ) are subjected to NVE dynamics (the half region including the solid/ liquid interface $)^{55}$. In our NVE/T MD simulations, the temperature control was implemented by separated Nose-Hoover four-element chain thermostats for each molecule with all four time constants equal to 1 ps (refs 56-59).

Interaction energy calculation. In addition, independent test MD simulations (all $1 \mathrm{~ns}$ ) were carried out to compute average interaction energy of an ion with the surrounding water molecules in the bulk ice $E_{\mathrm{X} \text {-ice }}($ Fig. $4 \mathrm{~d}, \mathrm{e})$. For these test MD simulations, the system consists of 430 water molecules (representing bulk ice phase), $1 \mathrm{Na}^{+}$and 1 anion $\left(\mathrm{F}^{-}, \mathrm{Br}^{-}\right.$or $\left.\mathrm{I}^{-}\right)$. The initial configuration was prepared by replacing two tagged water molecules in ice with $1 \mathrm{Na}^{+}$and 1 anion. These test MD simulations were performed at a constant pressure and temperature $(N P T)$ ensemble with using the conventional Nosé-Hoover thermostat $\left(-13^{\circ} \mathrm{C}\right)$. The last $100 \mathrm{ps}$ data (50 configurations) were collected for the averaged potentialenergy calculations. Another series of test MD simulations using the same system size were performed with slightly different Lennard-Jones energy $(\varepsilon)$ and particle-size $(\sigma)$ parameters of the anions (Supplementary Fig. 15). The Gromacs software was utilized for these test MD simulations.

Data availability. The data that support the findings of this study are available on request from the corresponding authors (J.W or X.C.Z.).

\section{References}

1. Doherty, R. et al. Current issues in recrystallization: a review. Mater. Sci. Eng. A 238, 219-274 (1997).

2. Bartels-Rausch, T. et al. Ice structures, patterns, and processes: A view across the icefields. Rev. Mod. Phys. 84, 885-944 (2012).

3. Rollett, A. et al. Recrystallization and Related Annealing Phenomena (Elsevier, 2004)

4. Dash, J. G., Rempel, A. W. \& Wettlaufer, J. S. The physics of premelted ice and its geophysical consequences. Rev. Mod. Phys. 78, 695-741 (2006).

5. Knight, C. A., DeVries, A. L. \& Oolman, L. D. Fish antifreeze protein and the freezing and recrystallization of ice. Nature 308, 295-296 (1984).

6. Worrall, D. et al. A carrot leucine-rich-repeat protein that inhibits ice recrystallization. Science 282, 115-117 (1998).

7. Deller, R. C. et al. Synthetic polymers enable non-vitreous cellular cryopreservation by reducing ice crystal growth during thawing. Nat. Commun. 5, 3244 (2014).

8. Balcerzak, A. K. et al. Designing ice recrystallization inhibitors: from antifreeze (glyco) proteins to small molecules. RSC Adv. 4, 42682-42696 (2014).

9. Budke, C. et al. Quantitative efficacy classification of ice recrystallization inhibition agents. Cryst. Growth Des. 14, 4285-4294 (2014).

10. Miller-Livney, T. \& Hartel, R. W. Ice recrystallization in ice cream: interactions between sweeteners and stabilizers. J. Dairy Sci. 80, 447-456 (1997).

11. Blunier, T. et al. Asynchrony of Antarctic and Greenland climate change during the last glacial period. Nature 394, 739-743 (1998).

12. Shcherbina, A. Y., Talley, L. D. \& Rudnick, D. L. Direct observations of North Pacific ventilation: brine rejection in the Okhotsk Sea. Science 302, 1952-1955 (2003).

13. Tolbert, M. A., Rossi, M. J. \& Golden, D. M. Antarctic ozone depletion chemistry: reactions of $\mathrm{N}_{2} \mathrm{O}_{5}$ with $\mathrm{H}_{2} \mathrm{O}$ and $\mathrm{HCl}$ on ice surfaces. Science 240, 1018-1021 (1988).

14. Voorhees, P. W. The theory of Ostwald ripening. J. Stat. Phys. 38, 231-252 (1985).

15. Wettlaufer, J. S. Impurity effects in the premelting of ice. Phys. Rev. Lett. 82, 2516-2519 (1999).

16. Baker, I., Cullen, D. \& Iliescu, D. The microstructural location of impurities in ice. Can. J. Phys. 81, 1-9 (2003).

17. Durand, G. et al. Effect of impurities on grain growth in cold ice sheets. J. Geophys. Res. Earth Surf. 111, F01015 (2006).

18. Blake, D. F. \& DeVincenzi, D. L. Occurrence and Forms of Water and Ice on the Earth and Beyond, and the Origin (s) of Life. Available at https://ntrs.nasa.gov/ search.jsp?R=20020061364 (NASA, 1998).

19. Buch, V. et al. Clathrate hydrates with hydrogen-bonding guests. Phys. Chem. Chem. Phys. 11, 10245-10265 (2009).

20. Wooldridge, P. J., Richardson, H. H. \& Devlin, J. P. Mobile Bjerrum defects: a criterion for ice-like crystal growth. J. Chem. Phys. 87, 4126-4131 (1987).

21. Hofmeister, F. Zur lehre von der wirkung der salze. Arch. Exp. Pathol. Pharmacol. 25, 1-30 (1888).

22. Zhang, Y. \& Cremer, P. S. Chemistry of Hofmeister anions and osmolytes. Ann. Rev. Phys. Chem. 61, 63-83 (2010).

23. Cacace, M. G., Landau, E. M. \& Ramsden, J. J. The Hofmeister series: salt and solvent effects on interfacial phenomena. Q. Rev. Biophys. 30, 241-277 (1997).

24. Tobias, D. J. \& Hemminger, J. C. Chemistry. Getting specific about specific ion effects. Science 319, 1197-1198 (2008).

25. Jungwirth, P. \& Tobias, D. J. Specific ion effects at the air/water interface. Chem. Rev. 106, 1259-1281 (2006).
26. Piatkowski, L. et al. Extreme surface propensity of halide ions in water. Nat. Commun. 5, 4083 (2014).

27. Tielrooij, K. J. et al. Cooperativity in ion hydration. Science 328, 1006-1009 (2010).

28. He, Z. et al. Tuning ice nucleation with counterions on polyelectrolyte brush surfaces. Sci. Adv. 2, e1600345 (2016).

29. Zhang, H. et al. Aligned two- and three-dimensional structures by directional freezing of polymers and nanoparticles. Nat. Mater. 4, 787-793 (2005).

30. Shen, X. et al. Assembly of colloidal nanoparticles directed by the microstructures of polycrystalline ice. ACS Nano 5, 8426-8433 (2011).

31. Geidobler, R. \& Winter, G. Controlled ice nucleation in the field of freezedrying: fundamentals and technology review. Eur. J. Pharm. Biopharm. 85, 214-222 (2013).

32. Halloran, J. Making better ceramic composites with ice. Science 311, 479-480 (2006).

33. Bai, H. et al. Bioinspired large-scale aligned porous materials assembled with dual temperature gradients. Sci. Adv. 1, e1500849 (2015).

34. Knight, C. A., Hallett, J. \& DeVries, A. L. Solute effects on ice recrystallization: An assessment technique. Cryobiology 25, 55-60 (1988).

35. Parsons, D. F. et al. Hofmeister effects: interplay of hydration, nonelectrostatic potentials, and ion size. Phys. Chem. Chem. Phys. 13, 12352-12367 (2011).

36. Rios, P. R. et al. Nucleation and growth during recrystallization. Mater. Res. 8, 225-238 (2005)

37. Cobb, A. W. \& Gross, G. W. Interfacial electrical effects observed during the freezing of dilute electrolytes in water. J. Electrochem. Soc. 116, 796-804 (1969).

38. Wilson, P. W. \& Haymet, A. D. J. Workman-Reynolds freezing potential measurements between ice and dilute salt solutions for single ice crystal faces. J. Phys. Chem. B 112, 11750-11755 (2008).

39. Koop, T. et al. Water activity as the determinant for homogeneous ice nucleation in aqueous solutions. Nature 406, 611-614 (2000).

40. Vrbka, L. \& Jungwirth, P. Brine rejection from freezing salt solutions: a molecular dynamics study. Phys. Rev. Lett. 95, 148501 (2005).

41. Bartels-Rausch, T. et al. A review of air-ice chemical and physical interactions (AICI): liquids, quasi-liquids, and solids in snow. Atmos. Chem. Phys. 14, 1587-1633 (2014).

42. Parenteau-Bareil, R., Gauvin, R. \& Berthod, F. Collagen-based biomaterials for tissue engineering applications. Materials 3, 1863-1887 (2010).

43. Miyata, T., Taira, T. \& Noishiki, Y. Collagen engineering for biomaterial use. Clin. Mater. 9, 139-148 (1992)

44. Wang, F. et al. Porous $\mathrm{SiC}$ ceramics prepared via freeze-casting and solid state sintering. Ceram. Int. 42, 4526-4531 (2016).

45. Yao, D. et al. Fabrication porous $\mathrm{Si}_{3} \mathrm{~N}_{4}$ ceramics via starch consolidation-freeze drying process. Mat. Lett. 68, 75-77 (2012).

46. Deville, S. Ice-templating, freeze casting: beyond materials processing. J. Mat. Res. 28, 2202-2219 (2013).

47. O'Brien, F. J. et al. The effect of pore size on cell adhesion in collagen-GAG scaffolds. Biomaterials 26, 433-441 (2005).

48. Murphy, C. M., Haugh, M. G. \& O’Brien, F. J. The effect of mean pore size on cell attachment, proliferation and migration in collagen-glycosaminoglycan scaffolds for bone tissue engineering. Biomaterials 31, 461-466 (2010).

49. Oh, H. H. et al. Preparation of porous collagen scaffolds with micropatterned structures. Adv. Mater. 24, 4311-4316 (2012).

50. Tam, R. Y. et al. Solution conformation of C-linked antifreeze glycoprotein analogues and modulation of ice recrystallization. J. Am. Chem. Soc. 131, 15745-15753 (2009)

51. Congdon, T., Notman, R. \& Gibson, M. I. Antifreeze (glyco) protein mimetic behavior of poly (vinyl alcohol): detailed structure ice recrystallization inhibition activity study. Biomacromolecules 14, 1578-1586 (2013).

52. Plimpton, S. Fast parallel algorithms for short-range molecular dynamics. J. Comput. Phys. 117, 1-19 (1995).

53. Hess, B. et al. LINCS: a linear constraint solver for molecular simulations. J. Comput Chem. 18, 1463-1472 (1997).

54. Essmann, U. et al. A smooth particle mesh Ewald method. J. Chem. Phys. 103, 8577-8593 (1995).

55. English, N. J. \& MacElroy, J. M. Theoretical studies of the kinetics of methane hydrate crystallization in external electromagnetic fields. J. Chem. Phys. 120, 10247-10256 (2004).

56. Rozmanov, D. \& Kusalik, P. G. Temperature dependence of crystal growth of hexagonal ice $\left(\mathrm{I}_{\mathrm{h}}\right)$. Phys. Chem. Chem. Phys. 13, 15501-15511 (2011).

57. Rozmanov, D. \& Kusalik, P. G. Anisotropy in the crystal growth of hexagonal ice, $\mathrm{I}_{h}$. J. Chem. Phys. 137, 094702 (2012).

58. Martyna, G. J., Klein, M. L. \& Tuckerman, M. Nosé-Hoover chains: the canonical ensemble via continuous dynamics. J. Chem. Phys. 97, 2635-2643 (1992).

59. Jang, S. \& Voth, G. A. Simple reversible molecular dynamics algorithms for Nosé-Hoover chain dynamics. J. Chem. Phys. 107, 9514-9526 (1997). 


\section{Acknowledgements}

We are grateful for the financial support from the 973 Program (2013CB933800), the National Natural Science Foundation of China (Grant Nos. 51436004 and 21421061), the Strategic Priority Research Program of the Chinese Academy of Sciences (Grant

XDA09020000), the US National Science Foundation (CHE-1500217, CBET-1512164), as well as a fund from Beijing Advanced Innovation Center for Soft Matter Science \& Engineering for summer visiting scholar. The computational work is done at the University of Nebraska Holland Computing Center.

\section{Author contributions}

J.W. initiated the idea of investigating the effect of ions on ice recrystallization and supervised the experiments. X.C.Z. and J.S.F. supervised the MD simulation. S.W. and H.X. carried out the experiments. C.Z. carried out the MD simulation. S.W., C.Z., X.C.Z. and J.W. wrote the manuscript. S.W. and C.Z. contributed equally. All authors analysed and discussed the results.

\section{Additional information}

Supplementary Information accompanies this paper at http://www.nature.com/ naturecommunications
Competing interests: The authors declare no competing financial interests.

Reprints and permission information is available online at http://npg.nature.com/ reprintsandpermissions/

How to cite this article: $\mathrm{Wu}, \mathrm{S}$. et al. Ion-specific ice recrystallization provides a facile approach for the fabrication of porous materials. Nat. Commun. 8, 15154 doi: $10.1038 /$ ncomms15154 (2017).

Publisher's note: Springer Nature remains neutral with regard to jurisdictional claims in published maps and institutional affiliations.

\section{(c) (i)}

This work is licensed under a Creative Commons Attribution 4.0 International License. The images or other third party material in this article are included in the article's Creative Commons license, unless indicated otherwise in the credit line; if the material is not included under the Creative Commons license, users will need to obtain permission from the license holder to reproduce the material. To view a copy of this license, visit http://creativecommons.org/licenses/by/4.0/

(C) The Author(s) 2017 